\title{
Open Surgery for Retrieval of Patent Foramen Ovale Closure Device Embolized into Right Pulmonary Artery
}

\author{
Ahmad Al Khaddour ${ }^{1,2 *}$, Adelle Dawson ${ }^{1,2}$, Hussein El Shafei, \\ ${ }^{1}$ FRCS Glasg (C-Th), Damascus University Hospital/Locum Fellow, NHS Hospitals, Newcastle Underlym, UK \\ ${ }^{2}$ Damascus University Hospital, Damascus, Syria \\ Email: *ahmedal@doctors.org.uk
}

How to cite this paper: $\mathrm{Al} \mathrm{Khaddour,} \mathrm{A.,}$ Dawson, A. and El Shafei, H. (2017) Open Surgery for Retrieval of Patent Foramen Ovale Closure Device Embolized into Right Pulmonary Artery. World Journal of Cardiovascular Surgery, 7, 67-72.

https://doi.org/10.4236/wjcs.2017.75008

Received: January 19, 2017

Accepted: May 22, 2017

Published: May 25, 2017

Copyright $\odot 2017$ by authors and Scientific Research Publishing Inc. This work is licensed under the Creative Commons Attribution International License (CC BY 4.0).

http://creativecommons.org/licenses/by/4.0/

\begin{abstract}
Percutaneous Patent Foramen Ovate PFO/Atrial Septal Defect (ASD) closure has become an increasingly simplified procedure over the past decade. The main advantages of a percutaneous approach include avoidance of surgery, short procedure time and hospital stay. Device embolization is seen rarely but it can be fatal. We report this complication following a percutaneous PFO closure in a 44-year-old man. The device was embolized into the distal part of the right pulmonary artery. We removed the device surgically and closed the $\mathrm{PFO} / \mathrm{ASD}$.

\section{Keywords}

Patent Foramen Ovate, Atrial Septal Defect, Septal Closure Device, Embolization of the Right Pulmonary Artery, Amplatzer Device, Cardiopulmonary Bypass
\end{abstract}

\section{Introduction}

Patent Foramen Ovale (PFO) is found in around a quarter of the general population and may be implicated in some cerebrovascular events by the mechanism of paradoxical embolism. Similarly, Ostium Secundum Atrial Septal defect (ASD) is one of the most common congenital heart defects in adults [1] [3]. Percutaneous atrial septal defect (ASD) closure was first performed in 1974 [2] [3]. And percutaneous PFO closure in patients with suspected paradoxical embolism is now a common procedure in the developed world. The main advantages of percutaneous approach include avoidance of surgery, short procedure time and hospital stay and quick recovery time. Device embolization is seen rarely but it can be fatal. It is seen in about $0.6 \%$ of cases [1] [2]. And it could be 
as high as $20 \%$ [3]. We report a complication of such closure in a 44 -year-old man. The diagnosis of device embolization was made three months after implantation during a routine echocardiographic check up. The device embolized into the distal part of the right pulmonary artery. We removed the device surgically and closed the PFO.

\section{Case Presentation}

A 44 year old male was admitted to our hospital for a routine echocardiogram examination. The patient had undergone percutaneous PFO closure 3 months earlier in a different hospital. The patient's past medical history includes doudenitis and multiple cerebellar infarcts over the previous two years most likely due to paradoxical emboli. The presentation of these infarcts was: paraesthesia and numbness in the left side of the body, double vision, motion sickness and gait incoordination. There was full recovery of these symptoms prior to his PFO closure. On the evening of the PFO closure, he presented to the local hospital with vomiting and haematemesis. He underwent upper GI endoscopy which suggested a degree of oesophagitis, but no bleeding source was identified. He had a chest $\mathrm{x}$-ray as part of this assessment (Figure 1). Three months after implantation the patient underwent a routine saline bubble echocardiogram which demonstrated a large number of bubbles crossing from the right atrium to the left atrium, indicating a residual large interatrial shunt. The Amplatzer device was not visualized on transthoracic echocardiography which showed also left to right shunt and moderately dilated atria (Figure 2). Estimated right ventricular systolic pressure (RVSP) was $18 \mathrm{mmHg}$ with good left and right ventricular functions. The patient underwent Transoesophageal echocardiogram which

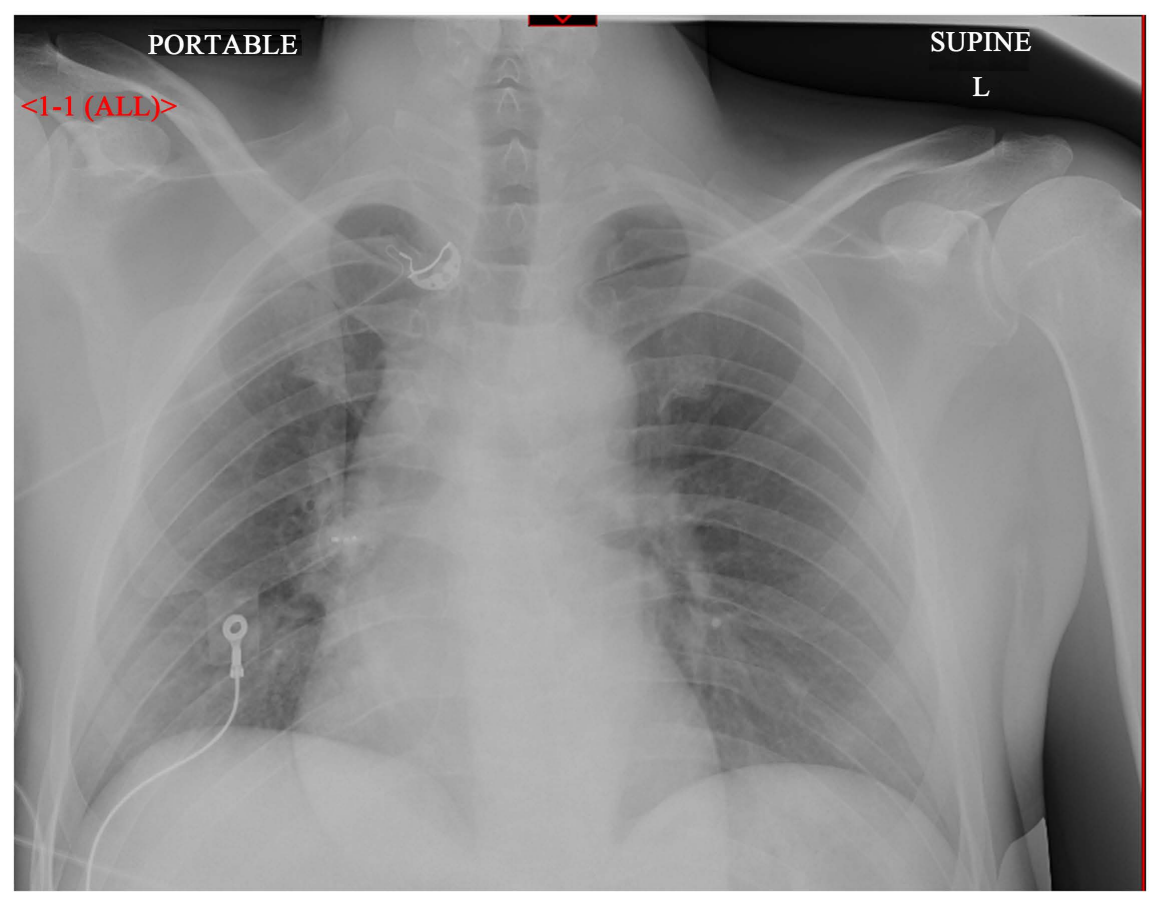

Figure 1. CXR the evening of the procedure. 


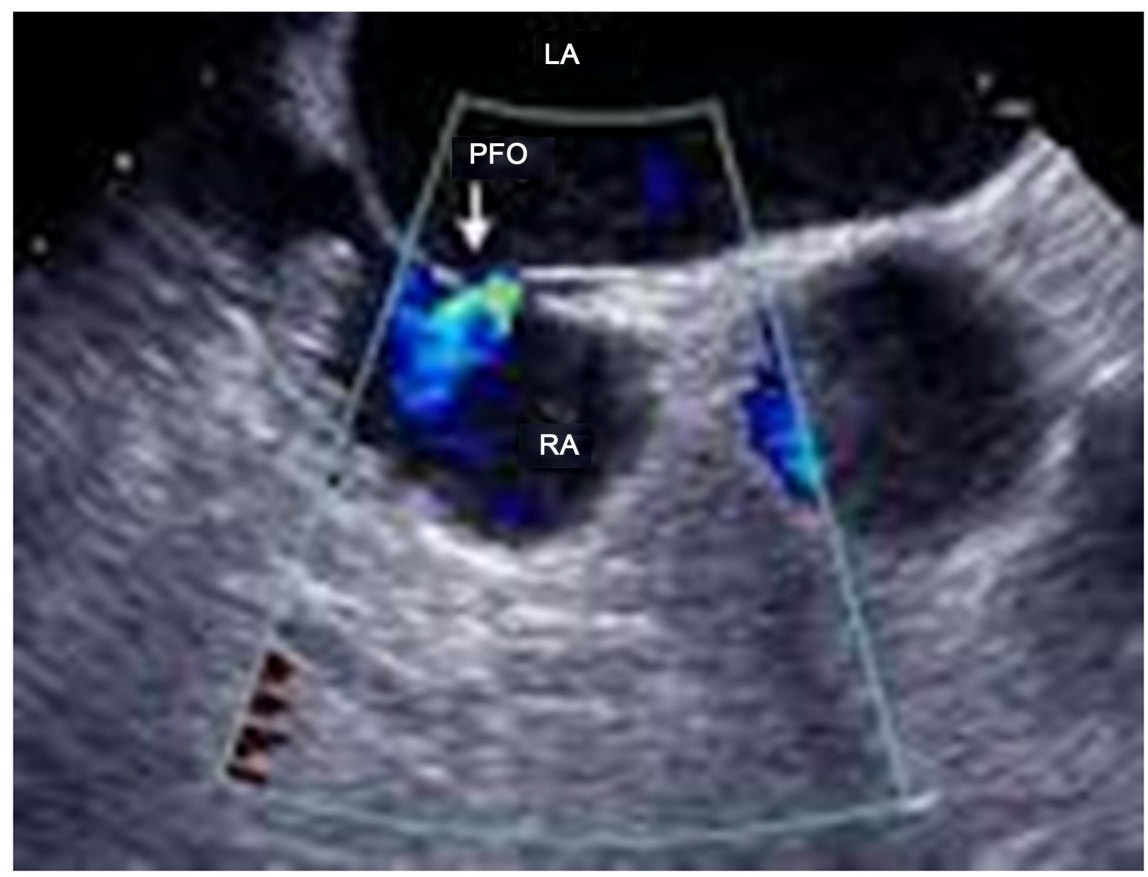

Figure 2. Transthoracic Echo before the open surgery. Amplatzer device was not visualised with left to right shunt through the PFO.

showed a large Patent Foramen Ovale (PFO) with spontaneous left to right shunt. The interatrial septum was markedly aneurysmal and there was no closure device in situ. An urgent Thoracic Computed Tomography study showed that the Amplatzer device had migrated to the distal part of the right pulmonary artery before its bifurcation into lobar branches (Figure 3). Percutaneous removal of the device was considered but the patient elected to have it surgically removed. The patient underwent a sternotomy procedure to remove the device and close the PFO. At operation the heart was enlarged with raised venous pressure. Systemic heparin was administered and cardiopulmonary bypass instituted using bicaval cannulation for venous drainage and an ascending aortic cannulation for arterial return. Systemic temperature was only allowed to drift. After institution of cardiopulmonary bypass (CPB) the device was palpated in the distal part of the right pulmonary artery beyond the pericardial reflection and lateral to the superior vena cava (SVC). It was firmly adherent and difficult to mobilize. The superior vena cava was adherent to the right pulmonary artery with an inflammatory reaction around it.

These resulted in lacerations in the SVC during passing a tape around it. These lacerations were subsequently controlled with plegetted sutures. On Cardio pulmonary bypass and beating heart, in order to reduce the time of cross clamp, the right pleura were opened. The distal part of the right pulmonary artery where the device was palpated was mobilized from the pericardial reflection and the pleura then arteriotomy was performed exactly over the device. The formed endothelialized pannus was cut and the $2.5 \mathrm{~cm}$ device was delivered (Figure 4). The lacerated arteriotomy was sutured with a series of plegetted " $5-0$ prolene" 


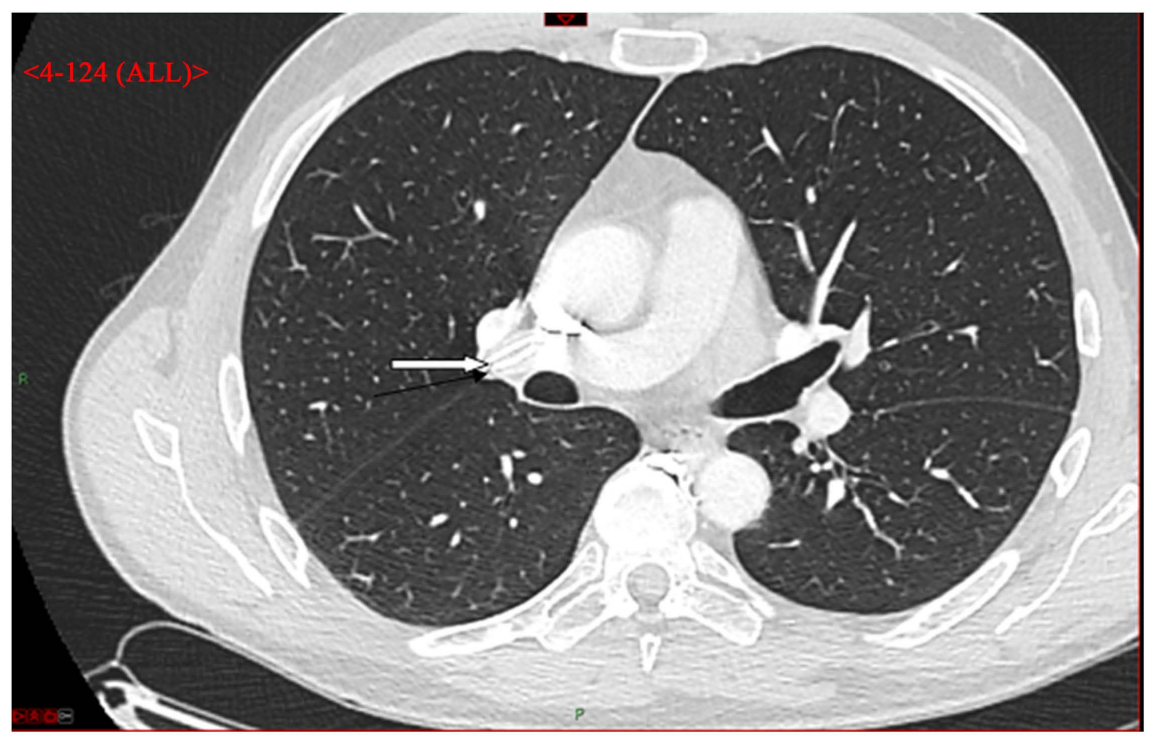

Figure 3. Chest CT scan showing the Amplatzer device stuck in the distal part of the right pulmonary artery.

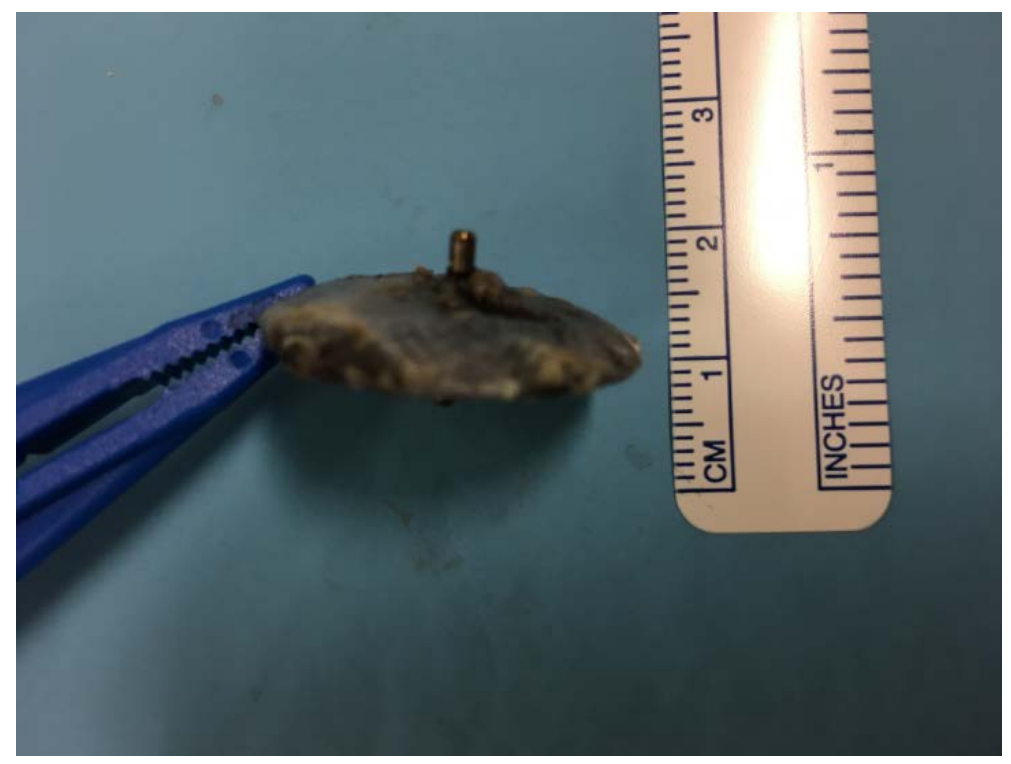

Figure 4. The removed $2.5 \mathrm{~cm}$ sharp edge device with formed endothelized pannus.

stitches and Evicel glue was added. Medtronic haemostatic patch was also applied over the suture line.

Aortic cross-clamp was then applied and antegrade cold blood cardioplegia infused to achieve cardiac arrest. The right atrium was opened. The patent foramen ovale defect was closed with direct suturing in two layers using " $4-0$ prolene" sutures.

The incision in the right atrium was sutured using " 4 - 0 prolene" suture. The cross-clamp was then released and the heart resumed beating in sinus rhythm. Cardiopulmonary bypass was discontinued without complications.

Three chest drains were inserted, haemostasis secured and the chest closed using 7 single sternal wires. The cross clamp time was 25 minutes and cardio- 
pulmonary bypass time was 165 minutes.

Post operatively the patient made a good recovery. On day four postoperatively, he developed atrial fibrillation for which he was treated with oral amiodarone. He reverted to sinus rhythm, and he was discharged home on the $7^{\text {th }}$ postoperative day. The patient attended the outpatient clinic six weeks following his discharge and he was stable and doing well.

\section{Discussion}

We reported this complication of such closure in a 44 year old man. The diagnosis of device embolization was made three months after implantation during a routine echocardiographic check-up. The device embolized into the distal part of the right pulmonary artery. This complication is seen in about $0.6 \%$ of cases of percutaneous PFO/ASD closure [1] [2]. And it could be up to $20 \%$ of cases [3]. Sometimes it can be fatal [1] [3]. The closure of a PFO/ASD by a percutaneous intervention may fail for several reasons. These reasons may include a very large defect, lack of strength of the rims of the septum to carry the device, and undersizing of the ASD device [1] [3]. The aortic rim is very important and a margin < $5 \mathrm{~mm}$ predisposes to both early and late device embolization [1] [3].

Patients at high risk of device embolization must be followed more carefully by echocardiography. In addition longer duration of avoidance from physical straining must be recommended [3]. We wonder whether our patient's episodes of vomiting/haematemesis had created the right haemodynamic conditions for early embolisation of the device. The chest $\mathrm{x}$-ray appearances provided a clue that the device may have embolised, but were not appreciated at the time. When this complication is discovered early, within first 24 hours; the percutaneous retrieval is possible in $50 \%$ of cases using devices like endomyocardial biopsy or different kinds of snares [2]. The surgical approach allows both retrieving the device and closing the PFO/ASD [1]. When this complication was discovered after three months, although percutaneous retrieval was considered, the surgical approach was chosen. In retrospect, percutaneous retrieval would have been unlikely to have been successful and might have resulted in serious and or fatal lacerations of the pulmonary artery. An open surgical procedure is the preferred method of retrieval when the diagnosis of device embolization is made late or when the position of the embolized device is in distal part of the right or left pulmonary artery.

The surgical approach allowed access and control of any injury during retrieval of an embolized device. It also allows concomitant closure of the septal defect [4]. We recommend that the removal process to be carried out on a beating heart on cardiopulmonary bypass $(\mathrm{CPB})$ and thus avoid a prolonged aortic cross clamp time.

\section{Conclusion}

Device embolization is a rare but potentially fatal complication of percutaneous $\mathrm{PFO} / \mathrm{ASD}$ closure. Although percutaneous retrieval is feasible in early presenta- 
tion, surgical removal is the preferred approach in late presentation. Percutaneous retrieval may be difficult and dangerous in late presentation. The patient was formally consented to report this case.

\section{References}

[1] Hamur, H., Onk, O., Degirmenci, H., Kahraman, U., Bakirci, E. and Tuncer, O. (2016) The Retrieval of Atrial Septal Defect Closur Device Embolized into Aortic Arch. Intractable \& Rare Diseases Research, 5, 114-116. https://doi.org/10.5582/irdr.2016.01016

[2] Son, J.W. and Park, J.S. (2012) Subacute Silent Embolization of Amplatzer Atrial Septal Defect Closure Device to the Pulmonary Artery. Journal of Cardiovascular Ultrasound, 20, 201-204. https://doi.org/10.4250/jcu.2012.20.4.201

[3] Sahin, D.Y., Koc, M., Cakir, H., Arik, O.Z., Elbasan, Z. and Cayli, M. (2012) A Silent and Late Embolization of Atrial Septal Defect Occluder Device into the Right Pulmonary Aretry: A Case Report. Korean Circulation Journal, 42, 781-783. https://doi.org/10.4070/kcj.2012.42.11.781

[4] Amanullah, M.M., Siddiqui, M.T., Khan, M.Z. and Atiq, M.A. (2011) Surgical Rescue of Embolized Amplatzer Devices. Journal of Cardiac Surgery, 26, 254-258. https://doi.org/10.1111/j.1540-8191.2011.01249.x

Submit or recommend next manuscript to SCIRP and we will provide best service for you:

Accepting pre-submission inquiries through Email, Facebook, LinkedIn, Twitter, etc. A wide selection of journals (inclusive of 9 subjects, more than 200 journals)

Providing 24-hour high-quality service

User-friendly online submission system

Fair and swift peer-review system

Efficient typesetting and proofreading procedure

Display of the result of downloads and visits, as well as the number of cited articles

Maximum dissemination of your research work

Submit your manuscript at: http://papersubmission.scirp.org/

Or contact wjcs@scirp.org 